\title{
CORRELATION OF COMPUTERISED TOMOGRAPHY SCAN FINDINGS WITH THE LEVEL OF CONSCIOUSNESS IN ACUTE HEAD TRAUMA
}

\author{
Vinayak Raje1 Devdutta Patil2, Trishant Chotai33, Rahul Kumar4, Shubhada Nalawade 5 \\ ${ }_{1}^{1}$ MCh, Department of Neurosurgery, KIMSDU, Karad. \\ ${ }^{2} 3^{\text {rd }}$ Year Postgraduate Student, Department of Neurosurgery, KIMSDU, Karad. \\ ${ }^{32}{ }^{\text {rd }}$ Year Postgraduate Student, Department of Neurosurgery, KIMSDU, Karad. \\ $41^{\text {st }}$ Year Postgraduate Student, Department of Neurosurgery, KIMSDU, Karad. \\ 51st Year Postgraduate Student, Department of Oral and Maxillofacial Surgery, KIMSDU, Karad.
}

\section{ABSTRACT}

\section{BACKGROUND}

Trauma is one of the most common causes of death and lifelong disability in early decades of life, of which majority of cases are neurological trauma. TBI is becoming the most common and devastating problem due to exponential growth in population and increased vehicle use. Head injuries due to road traffic accidents (RTA) are the second most common cause of death, only next to cancer. The present study was observational, prospective study undertaken to evaluate the correlation between CT scan findings and level of consciousness in patients following acute craniocerebral trauma.

The aim of this study is to correlate the CT scan findings and level of consciousness and to observe the outcome of the patient with single and multiple lesions.

\section{MATERIALS AND METHODS}

The study was conducted in Department of Neurosurgery, Krishna Medical College and Hospital. All the patients presenting to the hospital with history of head injury and admitted to Department of Neurosurgery were included as study population. Of all patients admitted with head injury and polytrauma, a careful history was collected from the patient and/or attendants to reveal the mechanism of injury and the severity of trauma. The patients were then assessed clinically to evaluate their general condition and the local injury. Glasgow coma scale, Glasgow outcome score and CT findings were evaluated.

Statistical analysis- The statistical analysis was performed using the Statistical Package for Social Sciences (SPSS) version 21 for Windows.

\section{RESULTS}

It was observed that majority of patients were in the age group of $21-40$ years $(55.65 \%)$ followed by $41-60$ years (20\%). The majority of patients were males (71.43\%) and females were $28.57 \%$. Patients had higher RTA incidences (72.40\%) followed by fall $(22.22 \%)$ and assault (5.38\%). In the clinical findings, majority of patients presented with vomiting (67.20\%) followed by loss of consciousness (38.74\%). The other clinical presentation includes ENT bleeding $(24.46 \%)$ and convulsion (18.34\%). The history of alcohol consumed was given by $23.48 \%$ of patients. It was observed that majority of patients were having abnormal CT findings $(80.74 \%)$ and only $19.26 \%$ patients had normal CT findings. The most common brain lesion among patients was cerebral contusion (46.74\%) followed by subdural haematoma (22.11\%), inter-parenchymal haematoma (12.34\%), subarachnoid haemorrhage (14.17\%), skull fractures $(8.06 \%)$ and midline shift $(30.28 \%)$. It was observed that majority of patients had mild injury $(73.72 \%)$ followed by severe type $(16.34 \%)$ and moderate injury among $174(9.94 \%)$ patients. According to outcome of brain injury, the majority of patients had good recovery (73.89\%). The death was observed among 198 (11.31\%) patients. It was observed that epidural haematoma, subdural haematoma, inter-parenchymal haematoma, SAH and IVH showed statistically significant relation with level of consciousness, $(\mathrm{p}<0.05)$. It was observed that pneumocephaly and midline shift showed statistically significant relation with level of consciousness $(p<0.05)$; while cerebral contusion, skull fractures and cerebral oedema showed no statistically significant relation with level of consciousness $(p>0.05)$.

\section{CONCLUSION}

Falls were considered the most common external cause of TBI in both the youngest and the elderly. The proportion of the transport accidents was highest in young men. The majority of hospitalised patients have mild TBI. A majority of the patients had good recovery. The correlation of CT findings and level of consciousness showed statistically significant relation with the level of consciousness. CT scanning is the primary modality of choice in the diagnostic workup of patients with acute traumatic brain injury for identification of various intracranial consequences, especially within 48 hours which helps in the initial assessment, treatment planning and follow-up and long-term management of patients.

\section{KEYWORDS}

Computed Tomography, Level of Consciousness, Acute Head Trauma.

HOW TO CITE THIS ARTICLE: Raje V. Patil D, Chotai T, et al. Correlation of computerised tomography scan findings with the level of consciousness in acute head trauma. J. Evolution Med. Dent. Sci. 2018;7(06):788-793, DOI: 10.14260/jemds/2018/179

'Financial or Other Competing Interest': None.

Submission 25-12-2017, Peer Review 24-01-2018,

Acceptance 31-01-2018, Published 05-02-2018.

Corresponding Author:

Dr. Devdutta Patil,

Department of Neurosurgery,

Krishna Institute of Medical Sciences, Karad-415110.

E-mail: drshubhadanlwd@gmail.com

DOI: $10.14260 /$ jemds $/ 2018 / 179$

\section{BACKGROUND}

Trauma is one of the most common causes of death and lifelong disability in early decades of life, of which majority of cases are neurological trauma.[1] TBI is becoming the most common and devastating problem due to exponential growth in population and increased vehicle use. Head injuries due to road traffic accidents (RTA) are the second most common cause of death, only next to cancer.[2] 
Head injury remains an important cause of death and disability in young adults, with over $50 \%$ of patients experiencing unfavourable outcomes. ${ }^{[3]}$ Studies have shown that nearly 1.6 million head injuries occur in the United States each year, resulting in over 50,000 deaths and over 70,000 patients with permanent neurological deficits.[2,3]

TBI accounts for up to $10 \%$ of the health care budget and an estimated annual cost to society of $\$ 30$ billion. ${ }^{[4]}$ Traumatic brain injury (TBI) is defined as an aggression to the brain caused by an external physical force that may produce a state of diminished or altered consciousness and consequently affecting cognitive abilities or physical function. It may be temporary or permanent, and may cause partial or total impairment of such functions.[1]

Traumatic brain injury constitutes one of the main health problems worldwide, currently with a high and increasing incidence, representing an important cause of morbidity and mortality among adolescents and young adults. It directly contributes to deaths by external causes. The main ones being car accidents, falls, aggressions and pedestrian run over. In Brazil in the year of 2008, the largest mortality rates due to such causes occurred in the Southeast and Northeast regions.[1] The initial assessment of a patient with TBI includes the Glasgow Coma Scale (GCS) data regarding the accident and computed tomography (CT). It is essential to determine the cause of the trauma, the impact intensity, presence of neurological symptoms, convulsion and particularly document any reports on loss of consciousness, [2] time elapsed between the accident and the examination, vomits and seizures.[3]

According to the GCS, traumatic brain injuries are classified as mild, moderate or severe. The GCS was initially described by Teasdale and Jennet in 1974, and is currently the most widely used parameter for assessment of consciousness level, as amongst its advantages it comprises a set of very simple and easy-to-perform physical examinations. ${ }^{[4]}$

Until 19 years ago radiography was the main imaging method recommended in emergency evaluations, where a sign of fracture was considered a risk factor. The protocols were then modified to include CT, GCS and the presence of cranial fracture as a risk factor.

Currently, the imaging method of choice for the diagnosis and prognosis of TBI is CT,[5] which is also instrumental in the management of the lesions progression. Results reported in studies investigating the indications of cranial CT in cases of TBI are controversial. Several studies attempt to establish clinical indicators to justify the non-use of cranial CT in certain cases of TBI as a contribution to costs reduction in the health system. ${ }^{[6,7,8,9]}$ The most recent protocols indicate CT within the first three hours following trauma in patients with GCS $<15$ and GCS= 15 presenting with one or more of the following findings: Convulsion, headache, vomiting, amnesia and/or syncope,[10] age group extremes, focal neurological deficit, suspicion of intoxication, visible cranial trauma and history of coagulopathies. [1]

Computed tomography findings in TBI vary according to the trauma severity, that is in accordance with the GCS score. Difficulties were experienced in comparison of tomographic findings, as there are only few scientific studies with that purpose in the literature. In the present study, effort was made to investigate such findings. The relationship among types of brain lesions demonstrated at CT, type of TBI (severity of the lesion) and prognosis are described by several authors in the literature,[11,12] all of them reporting approximately the same variation: the more severe the TBI is, more numerous and severe are the findings at CT.

So, aim and objective of my study is to correlate the computed tomographic findings with level of consciousness in acute head trauma.

\section{MATERIALS AND METHODS}

\section{Study Design}

The present study was observational prospective study undertaken to evaluate the correlation between CT scan findings and level of consciousness in patients following acute craniocerebral trauma. The study was conducted in Department of Neurosurgery, Krishna Medical College and Hospital.

\section{Study Population}

All the patients presenting to the hospital with history of head injury and admitted to Department of Neurosurgery were included as study population.

\section{Time Frame}

This study was carried out during July 2016 to June 2017 at Krishna Medical College and Hospital.

\section{Sample Size}

Total sample size was 1750 patients with history of head injury and admitted to Department of Neurosurgery during the study period were included in the study.

\section{Inclusion Criteria}

1. All patients with head injury and polytrauma.

2. Patients with acute craniocerebral trauma.

\section{Exclusion Criteria}

1. Conscious patients with grossly normal CT scan of head.

2. Pregnant women.

3. Patients with known bleeding disorder.

4. Patients who expired before the CT scan examination.

\section{Methods of Study}

- The selected subjects were visited and the questionnaire was administered after a written informed consent was obtained from the participants.

- All patients admitted with head injury and polytrauma, a careful history was collected from the patient and/or attendants to reveal the mechanism of injury and the severity of trauma.

- The patients were then assessed clinically to evaluate their general condition and the local injury.

\section{Glasgow Coma Scale (GCS)}

- $\quad$ Mild $=$ GCS score $\geq 13$

- $\quad$ Moderate $=$ GCS score 9-12

- $\quad$ Severe $=$ GCS score 3-8

\section{Glasgow Outcome Score}

- Grade I= Death.

- Grade II= Vegetative

- $\quad$ Grade III= Mostly Dependant. 
- $\quad$ Grade IV= Minimally dependant.

- Grade V= Good recovery.

\section{Statistical Analysis}

The statistical analyses was performed using the Statistical Package for Social Sciences (SPSS) version 21 for Windows. Data were expressed as mean values \pm standard deviations (SD) for continuous variables. Frequency and proportions were reported for categorical variables. The p-value of $<0.05$ was considered statistically significant using Chi-square test.

\section{RESULTS}

\begin{tabular}{|c|c|c|}
\hline Age Group & No. of Patients & Percentage \\
\hline $0-20$ & 210 & 12.00 \\
\hline $21-40$ & 974 & 55.65 \\
\hline $41-60$ & 350 & 20.00 \\
\hline$>60$ & 216 & 12.35 \\
\hline Total & $\mathbf{1 7 5 0}$ & $\mathbf{1 0 0}$ \\
\hline \multicolumn{3}{|c|}{ Table 1. Age Distribution } \\
\hline
\end{tabular}

The above table shows distribution of patients according to age. It was observed that majority of patients were in the age group of 21 - 40 years (55.65\%) followed by 41 - 60 years (20\%).

\begin{tabular}{|c|c|c|}
\hline Gender & No. of Patients & Percentage \\
\hline Male & 1250 & 71.43 \\
\hline Female & 500 & 28.57 \\
\hline Total & $\mathbf{1 7 5 0}$ & $\mathbf{1 0 0}$ \\
\hline \multicolumn{3}{|c|}{ Table 2. Gender Distribution } \\
\hline
\end{tabular}

The above table shows distribution of patients according to sex. It was observed that majority of patients were males (71.43\%) and females were $28.57 \%$.

\begin{tabular}{|c|c|c|}
\hline Cause & No. of Patients & Percentage \\
\hline RTA & 1267 & 72.40 \\
\hline Fall & 389 & 22.22 \\
\hline Assault & 94 & 05.38 \\
\hline Total & $\mathbf{1 7 5 0}$ & $\mathbf{1 0 0}$ \\
\hline \multicolumn{3}{|c|}{ Table 3. Cause of Head Injury } \\
\hline
\end{tabular}

The above table shows distribution of patients according to cause of head injury. It was observed that majority of patients had RTA (72.40\%) followed by fall $(22.22 \%)$ and assault (5.38\%).

\begin{tabular}{|c|c|c|}
\hline Clinical Findings & No. of Patients (n= 1750) & Percentage \\
\hline Vomiting & 1176 & 67.20 \\
\hline Convulsion & 321 & 18.34 \\
\hline ENT bleeding & 428 & 24.46 \\
\hline $\begin{array}{c}\text { Loss of } \\
\text { consciousness }\end{array}$ & 678 & 38.74 \\
\hline H/O of HTN & 362 & 20.68 \\
\hline Alcohol consumed & 411 & 23.48 \\
\hline \multicolumn{2}{|c|}{ Table 4. Clinical Findings at Presentation } \\
\hline
\end{tabular}

(*Multiple aetiologies present).

The above table shows clinical findings at presentation of patients. It was observed that majority of patients presented with vomiting $(67.20 \%)$ followed by loss of consciousness (38.74\%). The other clinical presentation includes ENT bleeding (24.46\%) and convulsion (18.34\%). The history of alcohol consumed was given by $23.48 \%$ of patients.

\begin{tabular}{|c|c|c|}
\hline CT Finding & No. of Patients & Percentage \\
\hline Normal & 337 & 19.26 \\
\hline Abnormal & 1413 & 80.74 \\
\hline Total & 1750 & 100 \\
\hline
\end{tabular}

The above table shows distribution of patients according to CT scan findings. It was observed that majority of patients were having abnormal CT findings (80.74\%) and only $19.26 \%$ patients had normal CT findings.

\begin{tabular}{|c|c|c|}
\hline Brain Lesion & No. of Patients (n= 1750) & $\mathbf{\%}$ \\
\hline Cerebral contusion & 818 & 46.74 \\
\hline Pneumocephaly & 73 & 04.17 \\
\hline Epidural haematoma & 124 & 07.08 \\
\hline Subdural haematoma & 387 & 22.11 \\
\hline $\begin{array}{c}\text { Inter-parenchymal } \\
\text { haematoma }\end{array}$ & 216 & 12.34 \\
\hline SAH & 248 & 14.17 \\
\hline IVH & 71 & 04.05 \\
\hline Skull Fractures & 141 & 08.06 \\
\hline Cerebral oedema & 636 & 36.34 \\
\hline \multicolumn{2}{|c|}{ Midline shift } & 530 \\
\hline Table 6. Distribution according to Type of Brain Lesions \\
\hline
\end{tabular}

(*Multiple aetiologies present).

The above table shows type of brain lesion. It was observed that most common brain lesions among patients was cerebral contusion (46.74\%). The other lesions were subdural haematoma (22.11\%), inter-parenchymal haematoma $(12.34 \%)$, subarachnoid haemorrhage $(14.17 \%)$, skull fractures (8.06\%) and midline shift (30.28\%).

\begin{tabular}{|c|c|c|}
\hline TBI & No. of Patients & \% \\
\hline Mild (GCS score $\geq 13$ ) & 1290 & 73.72 \\
\hline $\begin{array}{c}\text { Moderate } \\
\text { (GCS score 9 - 12) }\end{array}$ & 174 & 09.94 \\
\hline Severe (GCS score 3 - 8) & 286 & 16.34 \\
\hline Total & $\mathbf{5 0}$ & $\mathbf{1 0 0}$ \\
\hline \multicolumn{2}{|c|}{$\begin{array}{c}\text { Table 7. Distribution of Patients according to Type } \\
\text { of Brain Injury by GCS Score }\end{array}$} \\
\hline
\end{tabular}

The above table shows distribution of patients according to type of brain injury. It was observed that majority of patients had mild injury $(73.72 \%)$ followed by severe type $(16.34 \%)$ and moderate injury among 174 (9.94\%) patients.

\begin{tabular}{|c|c|c|}
\hline Outcome & No. of Patients & Percentage \\
\hline Grade I (death) & 198 & 11.31 \\
\hline Grade II (vegetative) & 16 & 00.91 \\
\hline $\begin{array}{c}\text { Grade III } \\
\text { (mostly dependant) }\end{array}$ & 106 & 06.06 \\
\hline $\begin{array}{c}\text { Grade IV (minimally } \\
\text { dependant) }\end{array}$ & 137 & 07.83 \\
\hline Grade V (good recovery) & 1293 & 73.89 \\
\hline Total & 1750 & 100 \\
\hline \multicolumn{3}{|c|}{$\begin{array}{l}\text { Table 8. Distribution of Patients according to } \\
\text { Outcome of Brain Injury }\end{array}$} \\
\hline
\end{tabular}


The above table shows distribution of patients according to outcome of brain injury. The majority of patients had good recovery (73.89\%). The death was observed among 198 (11.31\%) patients.

\begin{tabular}{|c|c|c|c|c|c|c|}
\hline \multirow{2}{*}{\multicolumn{2}{|c|}{ CT Findings }} & \multicolumn{3}{|c|}{\begin{tabular}{|l|} 
Level of Consciousness \\
\end{tabular}} & \multirow[b]{2}{*}{ Total } & \multirow{2}{*}{$\begin{array}{c}P \\
\text { value }\end{array}$} \\
\hline & & \multirow{2}{*}{$\begin{array}{c}\begin{array}{c}\text { Mild } \\
(\mathrm{n}=\mathbf{1 2 9 0})\end{array} \\
15\end{array}$} & \multirow{2}{*}{\begin{tabular}{|c|}
$\begin{array}{c}\text { Moderate } \\
(\mathbf{n}=\mathbf{1 7 4})\end{array}$ \\
31 \\
\end{tabular}} & \multirow{2}{*}{\begin{tabular}{|c|}
$\begin{array}{c}\text { Severe } \\
(\mathbf{n = 2 8 6})\end{array}$ \\
78
\end{tabular}} & & \\
\hline Epidural & Present & & & & 124 & \multirow{2}{*}{$<0.05$} \\
\hline haematoma & Absent & 1275 & 143 & 208 & 1626 & \\
\hline \multirow{2}{*}{$\begin{array}{c}\text { Subdural } \\
\text { haematoma }\end{array}$} & Present & 18 & 98 & 271 & 387 & \multirow{2}{*}{$<0.05$} \\
\hline & Absent & 1272 & 76 & 15 & 1363 & \\
\hline \multirow{2}{*}{$\begin{array}{c}\text { Inter- } \\
\text { parenchymal } \\
\text { haematoma }\end{array}$} & Present & 14 & 23 & 179 & 216 & \multirow[b]{2}{*}{$<0.05$} \\
\hline & Absent & 1276 & 151 & 107 & 1534 & \\
\hline \multirow{2}{*}{$\mathrm{SAH}$} & Present & 18 & 47 & 183 & 248 & \multirow{2}{*}{$<0.05$} \\
\hline & Absent & 1272 & 127 & 103 & 1502 & \\
\hline \multirow{2}{*}{ IVH } & Present & 03 & 12 & 56 & 71 & \multirow{2}{*}{$<0.05$} \\
\hline & Absent & 1287 & 162 & 230 & 1679 & \\
\hline \multicolumn{7}{|c|}{ Table 9. Correlation of CT Findings and Level of Consciousness } \\
\hline
\end{tabular}

The above table shows correlation of CT findings and level of consciousness. It was observed that epidural haematoma, subdural haematoma, inter-parenchymal haematoma, SAH and IVH showed statistically significant relation with level of consciousness $(p<0.05)$.

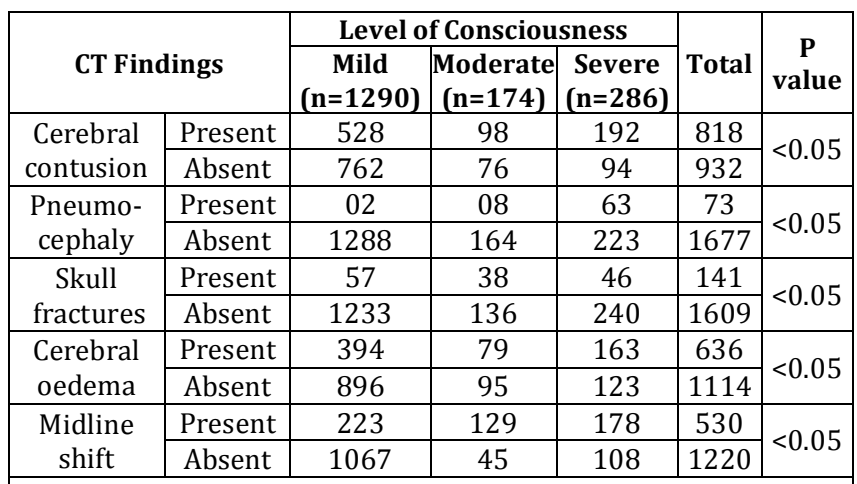

Table 10. Correlation of CT Findings and Level of Consciousness

The above table shows correlation of CT findings and level of consciousness. It was observed that pneumocephaly and midline shift showed statistically significant relation with level of consciousness ( $p<0.05)$; while cerebral contusion, skull fractures and cerebral oedema showed no statistically significant relation with level of consciousness ( $p>0.05)$.

\section{DISCUSSION}

Traumatic Brain Injuries (TBI) have been an important problem of public health for a long time. The correct and exact diagnosis of head trauma brain haemorrhage patients is necessary. It should be done correctly, but fast. For this purpose, CT scan is used as an important and non-aggressive method to diagnose and treat patients.

The present observational study was conducted to study the correlation of computed tomographic findings with level of consciousness in acute head trauma.

All patients admitted to Krishna Hospital with history of head trauma during the study period of August 2015 to August 2017 were included in the study.

A sample size of 1750 cases who were admitted in Neurosurgery Department in Krishna Hospital with head injury and polytrauma, both sexes were enrolled in the study.
Conscious patients with normal CT report of head, pregnant women, patients with known bleeding disorders, patients expired before CT scan were excluded from the study.

A written informed consent was obtained from the participant patient or his/her relatives. The study was approved by the Ethical Committee of the Institute. All the patients were investigated for basic investigations and special investigations like CT scan.

In the present study it was observed that majority of patients were in the age group of 21 - 40 years (55.56\%) followed by 41 - 60 years $(20 \%)$.

In a study done by Fabiana Lenharo Morgado et al on the correlation between the Glasgow Coma Scale and cranial computed tomographic findings in patients with traumatic brain injury observed mean age of the entire series was 37.77 \pm 18.69 years.

The majority of patients were males (71.43\%) and females were $28.57 \% .^{13}$

Navdeep Singh Saini et al studied factors predicting outcome in patients with severe head injury, where the majority of patients were males (85.45\%). ${ }^{14}$

Aiman Mohammed Imtiaz et al studied importance of computed tomography scans in acute traumatic brain injury and observed out of 100 cases included in the study $72 \%$ were males, while females constituted only $28 \% .15$

In a study done by Ali Jafari Khalilabadi et al on the relationship between CT scan findings, level of consciousness and outcome score in patients with traumatic brain haemorrhage observed out of 100 patients 36 were females and 64 were males with average age of 37 years. ${ }^{16}$

In a study done by Fabiana Lenharo Morgado et al on the correlation between the Glasgow Coma Scale and cranial computed tomographic findings in patients with traumatic brain injury observed among 102 patients prevalence of male patients was $80.4 \% .^{13}$

The majority of patients had RTA (72.40\%) followed by fall (22.22\%) and assault (5.38\%).

Navdeep Singh Saini et al studied factors predicting outcome in patients with severe head injury, where the majority of patients with road traffic accidents (83.64\%) is the most common mode of head injury. ${ }^{14}$

In a study done by Fabiana Lenharo Morgado et al on the correlation between Glasgow Coma Scale and cranial computed tomographic findings in patients with traumatic brain injury observed the most common causes of head injury were automobile accidents (52.9\%), falls $(20.6 \%)$, pedestrian injuries $(10.8 \%)$, falls to the ground $(7.8 \%)$ and aggression $(6.9 \%) \cdot{ }^{13}$

It was observed that majority of patients presented with vomiting $(67.20 \%)$ followed by loss of consciousness (38.74\%). The other clinical presentation includes ENT bleeding (24.46\%) and convulsion (18.34\%). The history of alcohol consumed was given by $23.48 \%$ of patients.

In a study done by Fabiana Lenharo Morgado et al on the correlation between the Glasgow Coma Scale and cranial computed tomographic findings in patients with traumatic brain injury observed most of the patients $(86.3 \%)$ presented with one or more risk factors related to the trauma (headaches, vomiting, convulsion, amnesia and/or syncope), and only $24.5 \%$ presented with one or more unrelated risk 
factors (coagulopathy, use of drugs or alcohol, previous neurological surgery, epilepsy, age $>50$ years, smoking). ${ }^{13}$

It was observed that majority of patients were having abnormal CT findings (80.74\%) and only $19.26 \%$ patients had normal CT findings.

Aiman Mohammed Imtiaz et al studied importance of computed tomography scans in acute traumatic brain injury and observed out of 100 cases 68 had positive CT scans. ${ }^{15}$

In a study done by Fabiana Lenharo Morgado et al on the correlation between the Glasgow Coma Scale and cranial computed tomographic findings in patients with traumatic brain injury observed tomographic findings were observed in $79.42 \%$ of the patients. ${ }^{13}$

In the present study, it was observed that most common brain lesion among patients was cerebral contusion (46.74\%). The other lesions were subdural haematoma (22.11\%), inter-parenchymal haematoma (12.34\%), subarachnoid haemorrhage (14.17\%), skull fractures (8.06\%) and midline shift (30.28\%).

Aiman Mohammed Imtiaz et al studied importance of computed tomography scans in acute traumatic brain injury and observed out of 100 cases $43 \%$ of the cases had brain contusion, $21 \%$ of the patients had subdural haematoma, $13 \%$ with subarachnoid haemorrhage, $4 \%$ had epidural haematoma, $12 \%$ of the patients had intracerebral haematoma and intraventricular haemorrhage and pneumocephalus was found to be the least common, $3 \%$ and $4 \%$ respectively. ${ }^{15}$

In a study done by Fabiana Lenharo Morgado et al on the correlation between the Glasgow Coma Scale and cranial computed tomographic findings in patients with traumatic brain injury observed among the studied patients, $79.42 \%$ $(81 / 102)$ had alterations reported at CT with $71.6 \%$ of them presenting subgaleal haematoma, $34.3 \%$ with craniofacial fractures $18.6 \%$ with subarachnoid haemorrhage, $10.8 \%$ with area of brain contusion with haemorrhagic suffusion, $7.8 \%$ with specific basilar skull fractures, 5.9\% with diffuse cerebral oedema and 5.9\% with extraparenchymal blood collection. ${ }^{13}$

In a study done by Ali Jafari Khalilabadi et al on the relationship between CT scan findings, level of consciousness and outcome score in patients with traumatic brain haemorrhage observed haematoma was subdural in $48 \%$ patients while epidural (44\%) and in $26 \%$ people was interparenchymal. ${ }^{16}$

The majority of patients had mild injury (73.72\%) followed by severe type (16.34\%) and moderate injury among 174 (9.94\%) patients.

In a study done by Fabiana Lenharo Morgado et al on the correlation between the Glasgow Coma Scale and cranial computed tomographic findings in patients with traumatic brain injury observed $82.4 \%$ of patients had traumatic brain injury rated as mild, $2.0 \%$ as moderate and $15.6 \%$ as severe. ${ }^{13}$

The majority of patients had good recovery (73.89\%). The death was observed among 198 (11.31\%) patients.

In a study done by Ali Jafari Khalilabadi et al on the relationship between CT scan findings, level of consciousness and outcome score in patients with traumatic brain haemorrhage death was reported for $13 \%$ people, vegetative state for $3 \%$ people, sever brain injury for $17 \%$ people, mild brain injury for $20 \%$ people and normal state for $47 \%$ people. ${ }^{16}$

The correlation of CT findings and level of consciousness showed that epidural haematoma, subdural haematoma, inter-parenchymal haematoma, SAH and IVH showed statistically significant relation with level of consciousness $(\mathrm{p}<0.05)$.

In a study done by Fabiana Lenharo Morgado et al on the correlation between the Glasgow Coma Scale and cranial computed tomographic findings in patients with traumatic brain injury observed statistical significance was observed in the correlation between the Glasgow Coma Scale and CT findings. ${ }^{13}$

The correlation of CT findings and level of consciousness showed that pneumocephaly and midline shift showed statistically significant relation with the level of consciousness ( $p<0.05$ ); while cerebral contusion, skull fractures and cerebral oedema showed no statistically significant relation with level of consciousness ( $p>0.05$ ).

In a study done by Ali Jafari Khalilabadi et al on the relationship between CT scan findings, level of consciousness and outcome score in patients with traumatic brain haemorrhage observed volume of haematoma in entrance and midline shift relates to patient's level of consciousness significantly and reversely. Increasing haematoma volume causes to fall level of consciousness more $(p=0.04, r=-0.62)$. Also increasing midline shift is followed by less level of consciousness $(\mathrm{p}=0.02, \mathrm{r}=-0.53) .{ }^{16}$

Navdeep Singh Saini et al studied factors predicting outcome in patients with severe head injury, where greater degree of midline shift on CT scan was associated with unfavourable outcome. This increase in unfavourable outcome with greater degree of midline shift is statistically important with $\mathrm{p}$ value $<0.005 .14$

Imaging is an important clinical tool used in the management of patients with TBI. Abnormal neurological examination is the most important criterion available to select patients for emergency CT. CT scanning is the primary modality of choice in the diagnostic workup of patients with acute traumatic brain injury for identification of various intracranial consequences, especially within 48 hours which helps in the initial assessment, treatment planning and follow-up and long-term management of patients.

\section{CONCLUSION}

The present observational study was conducted to study correlation of computed tomographic findings with level of consciousness in acute head trauma.

Falls were considered the most common external cause of TBI in both the youngest and the elderly. The proportion of the transport accidents was highest in young men. The majority of hospitalised patients have mild TBI. A majority of the patients had good recovery.

The correlation of CT findings and level of consciousness showed statistically significant relation with level of consciousness.

CT scanning is the primary modality of choice in the diagnostic workup of patients with acute traumatic brain injury for identification of various intracranial consequences, especially within 48 hours which helps in the initial assessment, treatment planning and follow-up and long-term management of patients. 


\section{REFERENCES}

[1] Leite CC, Amaro E, Lucato LT. Neurorradiologiadiagnóstico por imagem das alterações encefálicas. Rio de Janeiro: Guanabara Koogan; 2008:182-214.

[2] Foulkes MA, Eisenberg HM, Jane JA, et al. The traumatic coma data bank: design, methods, and baseline characteristics. J Neuro Surg 1991;75(Suppl 1):S8-13.

[3] Nitrini R, Bacheschi LA. A neurologia que todo médico deve saber. São Paulo: Editora Maltese, 1993.

[4] Teasdale G, Jennett B. Assessment of coma and impaired consciousness. A practical scale. Lancet 1974;2(7872):81-4.

[5] Hidayat S. Acute head trauma, an evaluation by CT scanning and conventional radiology. DMRD Dissertation, college of Medicine, Mosul University, Mosul. 1989.

[6] Sosin DM, Sniezek JE, Waxweiler RJ. Trends in death associated with traumatic brain injury, 1979 through 1992. Success and failure. JAMA 1995;273(22):1778-80.

[7] Barker PB. Fundamentals of MR spectroscopy. In: Gillard JH, Waldman AD, Barker PB, (eds). Clinical MR Neuroimaging. Cambridge: Cambridge university press, 2005:7-26.

[8] Centers for diseases control and Prevention. Traumatic brain injury: Colorado, Missouri, Oklahoma, and Utah, 1990-1993. MMWR 1997;46:8-11.

[9] Norlund A, Marke LA, Geijerstam JL, et al. Immediate computed tomography or admission for observation after mild head injury: cost comparison in randomised controlled trial. BMJ 2006;333(7566):469.
[10] Geijerstam JL, Oredsson S, Britton M. Medical outcome after immediate computed tomography or admission for observation in patients with mild head injury: randomised controlled trial. BMJ 2006;333(7566):465.

[11] Day AL, Rhoton AL. Aneurysms and arterio-veneous fistulas of the intracavernous carotid artery and its branches. In: Youmans JR. (eds). Neurological surgery. Vol 3. Saunders, Philadelphia, 1982:1764-8.

[12] Khalili AH. The value of a skull XR in the early management of head injury. Postgrad Doctor Middle East 1988;11:3891-3.

[13] Morgado FL, Rossi LA. Correlation between the glasgow coma scale and computed tomography imaging findings in patients with traumatic brain injury. Radiologia Brasileira 2011;44(1):35-41.

[14] Saini NS, Rampal V, Dewan Y, et al. Factors predicting outcome in patients with severe head injury: multivariate analysis. The Indian Journal of Neurotrauma 2012;9:45-8.

[15] Imtiaz AM. Trauma radiology: importance of computed tomography scans in acute traumatic brain injury. International Journal of Pharmaceutical Sciences and Business Management 2016;4(4):7-15.

[16] Khalilabadi AJ, Shahraki MK, Rezaeifard R, et al. The relationship between CT scan findings, level of consciousness and outcome score in patients with traumatic brain hemorrhage. Der Pharmacia Lettre 2016;8(20):140-4. 